\title{
Polycode as a multimodality of academic discourse
}

\author{
Elena Luchinskaya $^{1 *}$, Rosa Volkova $^{1}$, Bella Kabanyan ${ }^{1}$, and Yury Luchinsky ${ }^{1}$ \\ ${ }^{1}$ Kuban State University, Stavropolskaya str., 149, Krasnodar, 350040, Russia
}

\begin{abstract}
The article is devoted to the study of polycode in academic discourse. The purpose of the article is to describe polycode as one of the parameters of academic discourse, understood as a complex social and communicative activity in education. Academic discourse includes subjects, objects, and products of communication in a particular social environment. The article raises the question of the use of polycode in the educational environment at the university. Polycode is understood as a strategy, or a technique by which participants of communication are influenced by complex code systems. It is proved that in the terms of modern technological progress, new technologies help to use the effective ways of presenting information during academic discourse based on computer technologies, various resources and services, that is a combination of various semiotic codes. Linguocognitive and linguopragmatic approaches are actual in the determination and selection of semiotic codes, both verbal and non-verbal and necessary for certain educational situation. The study emphasizes that most modern texts are multimodal, created and represented by various semiotic codes and channels, as well as modes (image, writing, speech, etc.) of communication.
\end{abstract}

\section{Introduction}

The study shows that in the modern terms of digitalization and globalization of the higher education system, the growth of international academic mobility, integration and universalization of teaching technologies, a significant place in linguistic research is occupied by the issues of academic discourse, «the effectiveness and success of the construction of which are directly related to the positive results of knowledge acquisition», as well as its important role «in the prosperity of professional spheres of society, stability and progress of the future» [1]. According to K. Hyland, academic discourse changes our view of the world, becoming the main way of interpreting it and our place in it [2]. The problem of describing academic discourse is currently quite relevant due to the need to

\footnotetext{
*Corresponding author: bekketsam@yandex.ru
} 
determine effective ways of communication in the process of learning in higher education in the new conditions of its course - full-time or distance learning formats.

In the process of studying academic discourse, it was revealed that in a broad sense, this type of professional communication includes the whole complex of social and communicative activities in education, enlightenment and science, unites the subjects and objects of this activity, as well as its products [3]. K. Hyland relates academic discourse to the way of thinking and notes the ways of using language units in the educational sphere. The researcher emphasizes the use of different types of activities in the process of academic discourse, among which the main thing is to teach students using visual means in order to get acquainted with new scientific knowledge and competencies through language [4]. In some scientific works, scientific and academic discourses are considered as synonymous concepts. A different understanding of the notion of academic discourse is described in the work of N. V. Kazakova, who notes the mixed nature of AD similar to scientific discourse, in the process of which there is a scientific exchange of knowledge, represented, in particular, in scientific texts. However, it can also be considered as an educational discourse, which is based on texts of descriptive and explanatory specifics [5].

According to the article of P.V. Sysoev and O.O. Amerkhanova, the focus of scientific discourse is on the expression and interpretation of new scientific knowledge, while academic discourse is aimed at creating, expressing and interpreting scientific knowledge, in other words, at teaching [6]. We believe that «academic discourse is broader than scientific», "since science is one of the aspects of academic (educational) activity in society» [7]. Thus, in this study, we tend to understand academic discourse as all types of communication activities that occur within the academic sphere.

We understand the polycode of academic discourse as a strategy or a technique that help to affect the participants of communication with the help of a whole complex of code systems. Polycode in academic discourse reflects the use of different semiotic codes (verbal, visual, sound, etc.). As a result, the effect of the presence and involvement of students in the educational process is enhanced. Rapid technical progress and introduction of new technologies contribute to the creation of more effective ways of presenting information in academic discourse: combining written and oral texts, including infographics, educational animation in presentations, using photos and videos, hyperlinks, etc., based on resources and services in the educational process (Canva, Mindmeister, Google Drive, Moviemaker, Coggle, etc.), that is a combination of various semiotic codes.

The purpose of the given study is to define polycode as a parameter of academic discourse in the aspect of multimodality since this strategy has not yet been sufficiently studied in modern science and is incompletely described in linguistics despite a number of scientific works devoted to this issue. It is proved that polycode implies a combination of a language (verbal) code with the code of some other semiotic system, for example, a pictorial code.

Polycode as the genre of the Internet media was mentioned in the article by E.V. Prasolova [8]. Several researchers noted the linguistic-visual nature of polycode (Sladkova V.S., 2012, Natkho O.I. et al.). The analysis carried out shows that the polycode of the text includes interesting variants with mixed techniques. The study of modern texts shows the use of paralinguistic means, which combine with verbal means and form the content and pragmatic aspects. There are different types of mixing of verbal (literal) text and images in the science. The first one called parallel type in which the text and picture match. The second one is complementary or supplementary type in which the iconic information replaces or complements the verbal text. The third one is interpretive or explanatory type, it refers to the case when the text and the image are different in content [9]. Thus, creolized text includes verbal and non-verbal components. Visualization of the narration also refers to the polycode of the text in discourse. It is realized by including various photos in the text, 
forming its content and fulfilling its pragmatic aspect, in particular, performing emotional and expressive functions. The play of text graphics and the techniques of graphic imagery (replacing the standard text with graphon) is considered to be quite effective, the task of which is to draw attention and to highlight important information from a complex context. V.S. Sladkova notes that these visualization techniques reflect the inner world and cognitive space of a modern person immersed in «the world of virtual communication, cellular communication and computer technologies - forming and defining his life values» [9].

\section{Methods}

Linguocognitive and linguopragmatic approaches are basic ones in the process of determination and selection of semiotic codes, both verbal and non-verbal that are necessary for a particular discourse situation. In the process of studying polycode the discourse analysis, interpretation method, contextual analysis and text analysis were used to identify and describe the participation and effectiveness of verbal and non-verbal codes in various representations of academic discourse.

\section{Results}

During the given research it was shown that in academic discourse among multiple educational means the electronic educational resources are widely used. Modern educational environment promotes the integration of educational information with computer technologies, virtual libraries and databases. Mixed learning due to the polycode strategy in academic discourse contributes to greater efficiency and productivity of learning material leading to steady progress in teaching students. O.I. Natkho pointed out the functions of the main tools of the Moodle (Modular Object-Oriented Dynamic Learning Environment) software product, including informational, controlling and communicative ones [10].

Thus, researchers of discourses are trying to find out the degree of effectiveness and justification of the use of cognitive strategies for the perception and processing of various code systems. In addition, polycode is considered as a method of increasing manipulative influence in different-genre discourses (political, advertising, Internet, etc.). In science there are various tactics that take into account the correlation of the content of a verbal text and an image. Among them, for example, there is a complementary or supportive tactic the purpose of which is to add information through illustrative material to the content of an existing text. The second tactic can be understood as "transformative", because it helps to change the content of the text. The function of "diverting" tactics is to distract the addressee from the content of the verbal text [11].

Nowadays the person is involved in a variety of information flows in which the translation and perception of new information is realize through various semiotic systems that synchronously affect the consumer. Originally arose from the media discourse polycode as an actual characteristic of modern communication significantly influenced the ways of encoding information in other public spheres due to the emergence of new multimedia information and communication technologies and widespread computerization. Accoding to I.A. Gonchar «the search for ways to optimally present information has recently led to a kind of explosion of visual practices, where the visual image dominates over verbalized ways of transmitting information» [12]. The challenges of modern society which can be characterized as informative and communicative cause changes of the scientific approaches to the organization of academic communication by its participants and 
require conscious attitude and enhanced search for the new original structures and strategies of discourse generation.

Researchers distinguish this type of communication into a fundamentally new type of communication, separate from oral and written, speaking about network communication [13]. In the process of analyzing the academic discourse it was concluded that the new digital technologies possess a great didactic potential.

\section{Discussion}

The study of the polycode nature of academic discourse in multimodality aspect proves that the modern educational process can no longer be imagined without the use of computer technology. Professor possesses various skills, uses digital technologies to solve different pedagogical tasks not only for the preparation and production of accompanying material for lectures, seminars or conferences. Digital technologies allow him to use a new format of communication within the framework of academic discourse. Various mobile applications are used to develop students' types of thinking and critical introspection. The electronic identity technologies have become part of online learning required for proctoring and the elements of virtual reality are used as an element of mixed education. Today most courses involve working with technologies for processing large amounts of data (Big Data).

The implementation of digital technologies into the educational process makes it possible to determine the shift in focus in the field of modern linguistics. Multi-genre representations of a language should not be viewed separately. We can mention for instance the use of F. Benson's multimodal discourse analysis in the process of studying YouTube content, the objects of which are: a) various modes of YouTube, which included pictures, oral and written communication, music, active links, icons, etc .; b) a collective portrait of authors and methods of communication in the implementation of discourses, including comments of subscribers, advertising and evaluations (liking and disliking), and also c) taking into account the dynamics of the discourse itself (constantly changing content) [Cit. according to 17].

M.B. Voroshilova defines a polycode text as a complex form of "units of two or more different semiotic systems which enter into a relationship of interconnection, complementarity, mutual influence which causes a complex effect on the addressee" [14]. The structure of polycode texts is complex since they involve the means of different semiotic codes not only verbal, but also other (for example, iconic) codes which together make up "one visual, structural, semantic and functional unit aimed at a complex pragmatic impact on the addressee" [15].

Studying polycode as a necessary characteristic of modern communication and a strategic component in language education A. M. Arias and T. A. Ivanchenko draw attention to the fact that the visual code perception in written communication is more effective and it is explained by the different ways of interpretation of the image and interpretation of language. «Visual perception is a complex synthesizing activity demanding more information processing per unit of time than when interpreting a verbal text, so one of the main functions of the image is to attract and retain attention» [16].

However, according to some scholars there is the traditional priority position of speech and writing in Russian academic discourse [17], which indicates a certain degree of conservatism and inertia of such statements. In the social-semiotic world the central position of the verbal code is gradually disappears and the other means of constructing and explicating meanings takes a significant place today. This new tool has become to call «multimodality» [18].

Despite of the fact that the concept of «multimodality» was suggested by Gunther Kress and Theo van Leeuwen later they declared that there is no ambiguous definition of 
multimodality [18]. Subsequently G. Kress used the notion of a semiotic modus to clarify this phenomenon which includes «socially formed and culturally established semiotic resources for the production of meaning» [19]. So, for example, this modus takes into account not only the definition of the desired color and shape of the picture, but also the place and way of placing the picture on the page. Western researchers express the idea that multimodality can be distinguished as a new kind of genre. K. Jewet suggests that multimodality should be viewed from a theoretical perspective as a kind of perspective, or an area of research as a scientific method [Cit. according to: 17].

It is possible to clarify the history of assimilation of the term "multimodality" in Russian science through referring to the works of A.A. Kibrik. In the work "Multimodal linguistics" it is noted that multimodality involves awareness of «the difference between the human sense organs, primarily the visual and auditory channels $<\ldots>$ in speech, there is a segmental (verbal) component and many non-segmental (prosodic) parameters. The visual channel includes gestures, gaze, facial expressions, and other aspects of «body language». Written discourse is also perceived visually and, in addition to the verbal component, includes a whole set of graphic parameters, such as font, color, format, etc. In the process of creating creolized text, verbal components are skillfully combined with visual components, they have a special impact on the perception of the text. These include technical means of text design that affect its meaning: font, color, background of the text (colored or illustrated), means of spelling, punctuation and word formation, iconic printed symbols (pictograms, ideograms, infographics, etc.), graphic design of verbal text (in the form of a figure, for example), as well as line spacing - the difference between line height and font size. The modern concept of multimodality includes all this diversity» [20].

Here is an example of the use of infographics (Fig. 1) and the creation of a smart map (screenshot 1) used in academic discourse on the topic "Cognitive Research in Linguistics.

In 2014 a large-scale study entitled «Language as it is: Russian Multimodal Discourse» was carried out under the leadership of A.A. Kibrik. In the project the language research was carried out in the form of an oral multimodal discourse covering both the verbal component and non-verbal (visual) means of interaction. Subsequently, researchers began to use a new term - «multichannel discourse»: «Currently, the term «multimodal» is more common, but it is more correct to speak about «multichannel» or «bimodal» discourse, since so far only two modalities are mainly studied - vocal (auditory) and kinetic (visual), and the remaining modalities, for example, smell or touch, remain outside the scope of consideration» [21].

We fully agree with the opinion of I.P. Khutyz that the multimodality of academic discourse is the interaction of various semiotic systems that transmit information actual for the communicative norms of the society [22]. Speaking about communication event T.V. Vdovina emphasized, that multimodality is «a natural state of communication characterized by the co-presence of two or more semiotic modes or sign systems within a single communicative event (text)» [23]. The researcher claims that most modern texts are multimodal, that is, presented not only with the help of semiotic codes, but also transmitted through various channels. In addition, it is important to take into account the modes (image, writing, speech, etc.) of communication. «The world around us is multimodal, and we are multimodal organisms» [20]. 


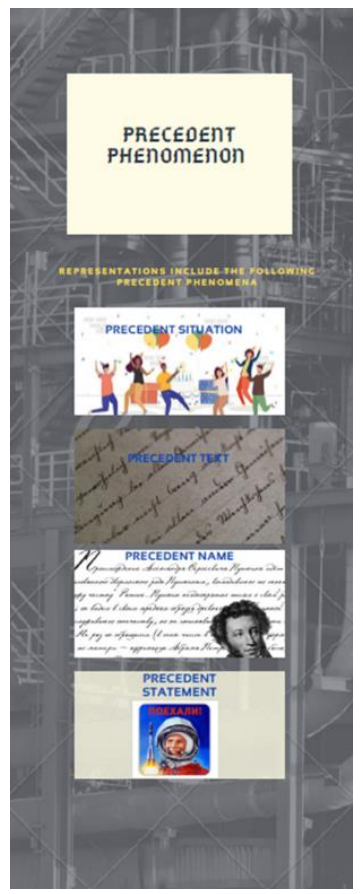

Fig. 1.

Precedent phenomena, Sourse: https://www.canva.com/design/DAEbW q6f44/share/preview?token=UR2HB1mLjv7dYdJ VJzXDw \&role=EDITOR\&utm_content=DAEbW_q6f44\&utm_campaign=designshare\&utm

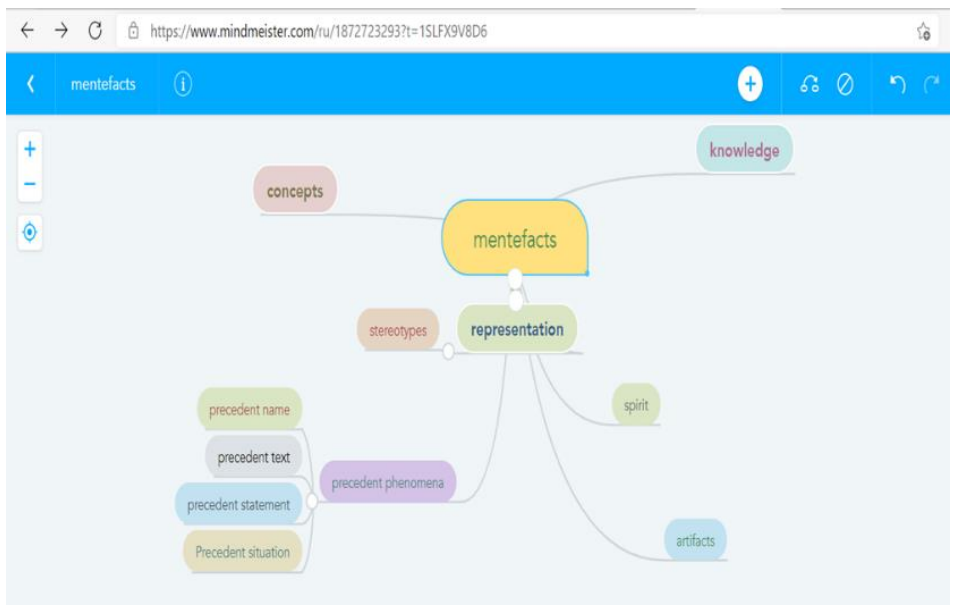

Fig. 2. Screenshot on the topic «Mentefacts», Sourse: http://mm.tt/1872723293?t=1SLFX9V8D6

\section{Results}

Indeed, the study of academic discourse has shown that both in everyday communication and in the business sphere taking into account the addressee factor we use various channels for successful communication which do not just participate in the transmission of 
information, but interact in a complex way and are interdependent, complement the information transmitted by each channel. «The presence of multiple modes contributes to complementarity in the design of modal ensembles: what is missing «here» in this mode is likely to be present «there» in another mode. Two or three (or even more) modes used in combination with each other can jointly provide the means to express what the message creator wants to express» [18]. In our opinion, the effectiveness of communication including academic communication directly depends on the ability of the participants of the discourse to optimally combine different modes, taking into account the goals and objectives set by the addressee and the sphere of communication. «Multimodal (digital, multimedia) text is fundamentally different from printed books, even if they are provided with colorful pictures. Its semantic range is extremely wide and variable; its individual components (picture, sound, video) can complement and intensify the message written in letters. But they can also compete with it to the point of giving the entire "message" the opposite meaning. ...By its nature, a multimodal text is closer not to written sources, but to oral communication, when a person is influenced not only by spoken speech, but also by gestures, facial expressions, physical features, and the position of the interlocutor in space" [24]. We believe that the polycode used in academic discourse has a positive impact on the participants in communication, and, first of all, students. The teacher guides and implements the educational process with the help of polycode texts using various channels of transfer of scientific knowledge thereby increasing the level of perception of the educational material by students, and, consequently, the positive effect of communication in general. Polycode in didactic practice presupposes the development of fundamentally new forms of transferring and mastering theoretical knowledge and practical skills which should have not only a verbal, but also a figurative presentation of information for the development of universal competencies of students.

The emergence of new multimedia information and communication technologies, globalization, mass computerization of all spheres of life makes it possible to speak of polycode as a cognitive and pragmatic technology that affects the ways of coding information [25]. As the study shows, academic discourse is implemented in various fields of activity of a scientist and a teacher. In this study, academic discourse is presented as a kind of institutional communication, during which different tasks are solved in an academic situation: new scientific knowledge is formed, transmitted by verbal and non-verbal means. Recent years have been marked by a sharp leap in the development of digital technologies and new forms of communication in the educational process. As a result of the studying of academic discourse, it was concluded that students give preference to polycode texts, because they are unusual and interesting, increase the content, visualization and factuality of educational material, help to attract and retain attention, thus providing sustainable motivation for learning activities.

\section{Conclusion}

In the course of the given research, it was concluded that the study of the polycode of academic discourse in the aspect of multimodality is prospective. In this regard it is necessary to focus not so much on the semiotic codes themselves, as on the study of the effectiveness of the simultaneous use of various means and technologies. Consequently, the polycode of academic discourse determines the appearance of the best results in a situation of communication with the addressee in order to achieve successful communication. It is interesting in the future to compare the effectiveness of the interaction of graphic, auditory, iconic and other codes on the addressee. We have to admit that today the priority is to understand the foundations of creating a multimodal text, as well as to search for new ways of its interpretation and perception by participants in academic discourse [26]. 
In the course of the analysis, it was concluded that polycode, understood as a strategy, technique or method of academic discourse, emphasizes the importance of various semiotic codes that explicitly or implicitly, to a certain extent, affect the channels of perception of participants in communication. Polycode intensifies not only the aesthetic function of the message, but also its informational significance, impacting the addressee, that is the participants in the academic discourse. Thus, in the process of implementing academic discourse, there is a possibility of rational use of various parameters of polycode, which allows emotional impact on students to optimize communication, to intensify interactivity and progress in learning.

\section{References}

1. I. Khutyz, Features of research and construction of actual types of discourse and their categories: monograph, 97-128 (2016)

2. K. Hyland, Continuum Companion to Discourse Analysis, 171-184 (2011)

3. A. Stebletsova, Bulletin of the Volgograd State University, 5, 5-13 (2020)

4. K. Hyland, Academic Discourse: English in a global context, 215 (2009)

5. N. Kazakova, Formation of institutional features of the scientific and educational discourse (based on the material of English grammars of the XVI-XIX centuries): abstract of the dissertation of the Candidate of Philology, 26 (2012)

6. P. Sysoev, O. Amirkhanova. Language and culture, 4, 149-169 (2016)

7. I. Khutyz. Features of research and construction of actual types of discourse and their categories, 98-128 (2016)

8. E. Prasolova. Philological sciences. Questions of theory and practice, 12, 171-174 (2015)

9. V. Sladkova. University readings, 07 (2012)

10. O. Natkho. University Readings, 07 (2012)

11. I. Vashunina. Teacher XXI century, 1, 339-346 (2016)

12. I. Gonchar. Philological class, 2, 62-65 (2015)

13. V. Kostomarov. Russian Language Journal 60, 141-147 (2010)

14. M. Voroshilova. Political creolized text: keys to reading: monograph, 194 (2013)

15. I. Anisimova. Linguistics of the text and intercultural communication (based on creolized texts), 129 (2013)

16. A. Arias, T. Ivanchenko. Sociology and Law, 3, 39-44 (2016)

17. V. Omelyanenko, E. Remchukova. Communicative studies, 3 (17), 66-78 (2018)

18. G. Kress. METHOD: Moscow Yearbook of Works from Social Science Disciplines, 8 (2018)

19. G. Kress. Multimodality. A Social Semiotic Approach to Contemporary Communication, 79 (2010)

20. A. Kibrik. Cognitive research, 4, 14-152 (2010)

21. A. Kibrik. Images of language and zigzags of discourse: a collection of scientific articles dedicated to the 70th anniversary of V.Z. Demyankov, 180-191 (2018)

22. I. Khutyz. Bulletin of the Adyghe State University, 1 (172), 90-95 (2016) 
23. T. Vdovina Discourse analysis: methodological analysis and prospects for the application of sociological research: author. dis. ... Cand. sociol. sciences. Moscow: Peoples' Friendship University of Russia, 23 (2012)

24. "New literacy": what is multimodal texts // State Institute of the Russian Language named after A.S. Pushkin: officer. website (2016) 28 July. URL: http://

www.pushkin.institute/news/detail.php?ID=5203

25. Y. Luchinsky; E. Luchinskaya; R. Patyukova. Indian Journal of Science and Technology, 27, (2016) doi: 10.17485/ijst/2016/v9i27/97702

26. E. Luchinskaya, et al. Amazonia Investiga, 22, 665-672 (2019) 